Article

\title{
Effects of Seed-Coating Preparations of Living Streptomyces globisporus on Plant Growth Promotion and Disease Control against Verticillium Wilt in Cotton
}

\author{
Qin Chen ${ }^{1,2}{ }^{\oplus}$, Shuang Bai ${ }^{2}$, Tian Zhang ${ }^{1}$, Chunmei Duan ${ }^{2,3}$, Juan Zhao ${ }^{4,5}$, Quanhong Xue ${ }^{2, *}$ and Yulong Li ${ }^{2, *}$ \\ 1 Northwest Land and Resources Research Center, Shaanxi Normal University, Xi'an 710119, China; \\ chenqin@snnu.edu.cn (Q.C.); zhangtiangis@163.com (T.Z.) \\ 2 College of Resources and Environment, Northwest A\&F University, Yangling 712100, China; \\ baishuang840527@163.com (S.B.); mduanchun40@163.com (C.D.) \\ 3 Ideological and Political Department, Xi'an Kedagaoxin University, Xi'an 710109, China \\ 4 College of Life Sciences, Northwest A\&F University, Yangling 712100, China; zhaojuan119882@163.com \\ 5 Institute of Plant and Environmental Protection, Beijing Academy of Agriculture and Forestry Sciences, \\ Beijing 100097, China \\ * Correspondence: xuequanhong@163.com (Q.X.); leeeyulong@163.com (Y.L.); Tel.: +86-29-8531-0659 (Q.X.)
}

Citation: Chen, Q.; Bai, S.; Zhang, T.; Duan, C.; Zhao, J.; Xue, Q.; Li, Y.

Effects of Seed-Coating Preparations of Living Streptomyces globisporus on Plant Growth Promotion and Disease Control against Verticillium Wilt in Cotton. Sustainability 2021, 13, 6001. https://doi.org/10.3390/su13116001

Academic Editor: Sara Magrini

Received: 19 April 2021

Accepted: 18 May 2021

Published: 26 May 2021

Publisher's Note: MDPI stays neutral with regard to jurisdictional claims in published maps and institutional affiliations.

Copyright: () 2021 by the authors. Licensee MDPI, Basel, Switzerland. This article is an open access article distributed under the terms and conditions of the Creative Commons Attribution (CC BY) license (https:// creativecommons.org/licenses/by/ $4.0 /)$.

\begin{abstract}
This study explored the role of viable cells and active metabolites in the seed-coating preparations of living Streptomyces globisporus in plant growth promotion and disease control against Verticillium wilt of cotton. Pot experiments were carried out to evaluate the effects of seed coating with living (LA), inactivated (IA), and 10-fold diluted living (DLA) preparations of S. globisporus Act7 and Act 28 on plant growth performance and disease index of cotton seedlings under attack by Verticillium dahliae. Compared with the control, leaf greenness was increased by $50.0-70.1 \%$ across all the three treatments of Act7 (LA7, IA7, and DLA7), and the leaf area of LA7- and DLA7-treated seedlings was increased by more than twice $(p<0.05)$. DLA7 also increased shoot weight by $62.2 \%$, while IA7 and DLA7 improved plant biomass by $30.4 \%$ and $72.1 \%$, respectively $(p<0.05)$. The root vitality of IA7- and DLA7-treated seedlings was enhanced by $69.1 \%$ and $75.8 \%$, respectively. The disease index of Verticillium wilt was reduced by 31.9\% (LA7), 25.0\% (IA7), and 66.7\% (DLA7) after treatments. The effects of Act28 preparations were similar to those of Act7 preparations. Through the combined action of viable spores and active metabolites, seed coating with an appropriate dose of living S. globisporusan can considerably promote plant growth and improve root vitality, while reducing the incidence of Verticillium wilt in cotton seedlings under attack by $V$. dahliae.
\end{abstract}

Keywords: continuous cotton cropping; soil sickness; Verticillium dahliae; Streptomyces globisporus; plant biomass

\section{Introduction}

Cotton (Gossypium hirsutum) is a major economic crop worldwide. It is difficult to change the practice of continuous cropping in high-quality cotton production areas. Verticillium dahliae Kleb., a soil-borne fungal pathogen that causes Verticillium wilt of cotton, can be enriched in the soil with increasing duration of cotton cropping. As a result, the infection of cotton plants is increasing year by year, which in turn causes serious economic losses [1,2]. Currently, it remains challenging to control the spread of Verticillium wilt in cotton using available methods, such as chemical control, genetic breeding, and optimization of the cropping pattern $[3,4]$. The development of Verticillium wilt as a soilborne disease of cotton is closely associated with the imbalance of soil microbiota due to an enrichment of $V$. dahlia and a depletion of beneficial microorganisms [5,6]. Therefore, by introducing specific beneficial microorganisms into the soil, it is possible to repress the growth of harmful pathogens and reconstruct healthy soil microbiota. This method 
is expected to effectively mitigate or eradicate Verticillium wilt of cotton and solve the problem associated with soil sickness in cotton fields under continuous cropping [7,8].

Actinomycetes occur extensively in the soil, and a high diversity of species have the ability to produce antibiotics. In particular, many studies have used Streptomyces species to control soil-borne diseases of crops because their spores are easy to isolate and germinate with high yield and long-term survival. In an earlier study, Zhao et al. [9] reported a Streptomyces strain Act28 (Streptomyces globisporus subsp. globisporus) with broad-spectrum resistance to plant fungal pathogens. In recent years, some Streptomyces species (Streptomyces roche D74 and Streptomyces partum Act12) were found to facilitate plant growth and enhance induced resistance in wheat [10], corn [11], and tomato [12]. In addition, members of the Streptomyces genus (Streptomyces partum Act12) demonstrated their ability to improve plant resistance to heavy metals [13], degrade allelopathic inhibitors from plant roots [14], and control parasitic weeds such as Orobanche coerulescens [15]. These studies demonstrate the potential value and broad prospects of Streptomyces species for application as biocontrol agents to control soil-borne diseases in crops.

Previously, we isolated several Streptomyces strains from the rhizosphere of cotton plants in Xinjiang and the extreme habitat in Northwest China. These environmental strains exhibited antagonistic activity against soil-borne fungal pathogens, including $V$. dahliae, which causes Verticillium wilt, and Fusarium oxysporum f. sp. vasinfectum, which causes Fusarium wilt in cotton [16,17]. Their effects on plant growth promotion and disease control were systematically studied through laboratory assays, pot experiments, and field experiments. Evidence suggested that the germination of $V$. dahliae was inhibited significantly by the cell-free culture filtrates of the Streptomyces strains [18]. In addition, they were able to grow with the biomass of fungal pathogens as a carbon and nitrogen source [19], and be induced by the pathogen to synthesize various extracellular hydrolases, which synergistically acted to drive the disintegration of fungal cell walls [20]. Moreover, the Streptomyces strains can colonize in cotton roots [21], enhance plant systemic resistance [17], and improve crop drought resistance [10,22], considerably promoting plant growth [23]. The above-mentioned studies have preliminarily elucidated the mechanisms of Streptomyces as biocontrol agents on plant growth promotion and disease control against Verticillium wilt of cotton. However, those studies were based on direct inoculation with living Streptomyces preparations, while the contributions of viable cells (spores) and active metabolites in the living preparations are still unclear.

In this study, we selected two Streptomyces strains to explore the effects of seed coating with live, inactivated, and diluted living preparations of Streptomyces on plant growth performance and $V$. dahliae-induced disease incidence in cotton seedlings by pot experiments. The aim of this study was to clarify the roles of viable spores and active metabolites present in the seed-coating preparations in promoting plant growth and controlling Verticillium wilt of cotton. The results will provide a data reference and technical support for field application of seed-coating preparations of living Streptomyces in cotton production.

\section{Materials and Methods}

\subsection{Test Strains and Seed-Coating Preparations}

Biocontrol strains: Two Streptomyces strains, Act7 and Act28, were isolated by our laboratory from the soil environment in the Qinghai-Tibet Plateau, China. Both strains showed broad-spectrum resistance to soil-borne plant pathogens, including $V$. dahliae and $F$. oxysporum [9]. Based on $16 \mathrm{~S}$ rDNA sequencing, strain Act28 was identified as Streptomyces globisporus subsp. globisporus [9], and strain Act7 was identified in the present study.

Seed-coating preparations: Strains Act7 and Act28 were cultured on Gauze's No. 1 agar plate for 7 days at $28^{\circ} \mathrm{C}$, and the biomass produced was freeze-dried and pulverized to obtain powder preparations of living Streptomyces. The number of viable spores in the Act7 and Act28 preparations was determined by the plate-count method $\left(1.0 \times 10^{11} \mathrm{cfu} \cdot \mathrm{g}^{-1}\right.$ and $3.2 \times 10^{9} \mathrm{cfu} \cdot \mathrm{g}^{-1}$, respectively). The living Streptomyces preparations were sterilized 
by dry heat at $170{ }^{\circ} \mathrm{C}$ for $2 \mathrm{~h}$ to obtain inactivated preparations. In addition, the living preparations were diluted 10 -fold using the respective inactivated preparations.

Pathogen: A highly pathogenic strain of Verticillium dahlia that causes deciduous-type Verticillium wilt of cotton was isolated from a disease area in Jingyang County, Shaanxi Province, China [17], by the team of Prof. Jiarong Yang (Northwest A\&F University, Yang Ling, China).

\section{2. $16 S$ rDNA Sequencing and Identification of Strain Act7}

The total DNA was extracted from strain Act7 by enzymatic digestion [24]. PCR amplification was performed using the universal bacterial primers Primer A: $5^{\prime}$-AGAGTTTGAT CCTGGCTCAG-3' and Primer B: 5'-AAGGAGGTGATCCAGCCGC-3'. The PCR products were sequenced by Sangon Biotech (Shanghai, China). The acquired sequences were aligned against the GenBank database. Sequence alignment was performed using Mega X, and phylogenetic trees were constructed using the neighbor-joining method.

\subsection{In Vitro Antagonistic Assays}

Confrontation culture assay: Strains Act7 and Act28 were inoculated on Gauze No. 1 agar plates and cultured upside-down at $28^{\circ} \mathrm{C}$. Ten days later, agar plugs with a diameter of $7 \mathrm{~mm}$ were prepared using a sterile punch. The agar plugs were placed on potato dextrose agar (PDA) plates after evenly spreading a spore suspension of $V$. dahlia on the plates. After incubation at $28^{\circ} \mathrm{C}$ for $72 \mathrm{~h}$, the transparency of the growth-inhibition zone was observed, and the diameter of this zone was measured.

Growth-inhibition assay: Strains Act7 and Act28 were inoculated into Erlenmeyer flasks containing modified bean broth medium No. 2 [25]. Fermentation was carried out at $28{ }^{\circ} \mathrm{C}$ on a $180 \mathrm{r} \cdot \mathrm{min}^{-1}$ shaker for 8 days. The fermentation broth was filtered through qualitative filter paper and then passed through a $0.22 \mu \mathrm{m}$ sterile filter membrane under aseptic conditions. The cell-free culture filtrates were mixed with 4 volumes of sterilized PDA medium, and an equal amount of sterile water was added to sterilized PDA medium as control. Agar plugs (7 mm diameter) of 3-day-old V. dahliae were placed on PDA plates containing the cell-free Streptomyces culture filtrates. After incubation at $28{ }^{\circ} \mathrm{C}$ for $72 \mathrm{~h}$, the diameter of $V$. dahliae colonies formed on the plates was measured.

Spore germination assay: A $1 \mathrm{~mL}$ aliquot of cell-free Streptomyces culture filtrates was aseptically diluted 10 -fold and then inoculated with $V$. dahliae spores using a sterile inoculation loop. After thorough mixing, the number of $V$. dahliae spores was counted under a $40 \times$ light microscope (30-50 spores). In the control group, $10 \mathrm{~mL}$ of sterile water was inoculated with an equal number of $V$. dahliae spores. After incubation at $28{ }^{\circ} \mathrm{C}$ for $16 \mathrm{~h}$, spore germination was observed by light microscopy.

\subsection{Pot Experiment}

Experimental design: The pot experiment consisted of seven treatments, in which cotton seeds were coated with: (1) a binding agent carboxymethylcellulose sodium (CM$\mathrm{CNa}$ ) without the Streptomyces preparations, designated as CK (control); (2) the living preparations of strains Act7, designated as LA7 (Living Actinomycetes Act7); (3) living preparations of strains Act28, designated as LA28 (Living Actinomycetes Act28); (4) the inactivated preparations of strains Act7, designated as IA7 (Inactivated Actinomycetes Act7); (5) the inactivated preparations of strains Act28, designated as IA28 (Inactivated Actinomycetes Act28); (6) the 10-fold diluted living preparations of strains Act7, designated as DLA7 (Dilution Living Actinomycetes Act28); and (7) the 10-fold diluted living preparations of strains Act28, designated as DLA28 (Dilution Living Actinomycetes Act28).

Seed coating: Seeds of cotton (Gossypium hirsutum) cultivar Xinluzao-17 were provided by Wanli Xu (Institute of Soil and Fertilizer, Xinjiang Academy of Agriculture and Forestry Sciences, Xinjiang, China). The cotton seeds were stored at room temperature before coating, then the plump cotton seeds $(1 \mathrm{~kg})$ were carefully selected and fully mixed with $250 \mathrm{~mL}$ of $6 \mathrm{~g} \cdot \mathrm{L}^{-1} \mathrm{CMCNa}$ solution; which were then transferred into a $1 \mathrm{~mm}$ soil sieve. 
The Streptomyces preparations were sprinkled into the sieve, and the sieve was shaken until the seeds were coated with the Streptomyces preparations uniformly. After that, the coated seeds were counted and the used Streptomyces preparations were weighed to determine the Streptomyces preparations used for each seed, which was usually at a rate of $90 \mathrm{mg} \cdot \mathrm{seed}^{-1}$ by repeated determination. The coated seeds were air-dried until the sowing.

Pot planting: Surface soil $(0-20 \mathrm{~cm})$ was collected from farmland in Yangling, China. The soil was classified as Eum-Orthic Anthrosol, equivalent to an Udic Haplustalf in the USDA system. The basic physicochemical characteristics of the topsoil at the $0-20 \mathrm{~cm}$ depth within the Guanzhong Plain on the Loess Plateau can be seen in [26]. After removing stones and plant debris, the soil was passed through a $1 \mathrm{~mm}$ sieve and added with manure $\left(15 \mathrm{~g} \cdot \mathrm{kg}^{-1}\right)$, urea $\left(0.25 \mathrm{~g} \cdot \mathrm{kg}^{-1}\right)$, and phosphate fertilizer $\left(0.50 \mathrm{~g} \cdot \mathrm{kg}^{-1}\right) . V$. dahliae hyphae were harvested from PDA plates and mixed with $20 \mathrm{~g}$ of perlite powder to give a final concentration of $5 \times 10^{10} \mathrm{~g}^{-1}$. The $V$. dahliae-containing perlite powder was thoroughly mixed with the experimental soil at a mass ratio of 1:1, and successively diluted to $35 \mathrm{~kg}$ of $V$. dahliae-infected soil $\left(2.9 \times 10^{7} \mathrm{~g}^{-1}\right)$. Cotton seeds were sown in pots with a $13.5 \mathrm{~cm}$ internal diameter containing $1.5 \mathrm{~kg}$ of infected soil each ( 5 seeds per pot). After emergence, 3 seedlings were retained in each pot. There were 3 pots per treatment. The potting experiment was conducted under outdoor conditions with daily watering management. The location was on the Guanzhong Plain on the Loess Plateau, which has a continental monsoon climate with a mean annual temperature, precipitation, and evaporation of $13.0{ }^{\circ} \mathrm{C}, 632 \mathrm{~mm}$, and $990 \mathrm{~mm}$, respectively. The potting experiment was set up with a completely randomized block design, and the position of each plot was changed randomly every 5 days. The potting experiment lasted for 60 days.

\subsection{Plant Physiological and Biochemical Measurements}

Leaf area and greenness: Leaf length and width were measured when the second true leaf was unfolded on the top of the cotton seedling, and leaf area was calculated as leaf length $\times$ leaf width. The leaf greenness index (SPAD value) was measured using a SPAD-502 chlorophyll meter [27].

Root vitality: After the measurement of plant biomass, the fibrous roots of cotton were cut and mixed thoroughly. A $0.5000 \mathrm{~g}$ sample of the roots was used to determine root vitality by triphenyltetrazolium chloride assay [28].

\subsection{Data Analysis}

The incidence and severity of Verticillium wilt were surveyed, and the disease severity was graded according to the extent of stem and leaf wilt: 0 for no wilted leaves, 1 for $<50 \%$ wilted leaves, 2 for $50-100 \%$ wilted leaves without stem wilt, and 3 for $100 \%$ wilted leaves with stem wilt [29]. Three cotton plants were planted in each pot, and 3 pots were repeated for each treatment, so 9 plants were repeated in total for each treatment. All 9 of the plants were investigated for each treatment, then the disease index was calculated using Equation (1). The germination rate of spores was calculated using Equation (2).

$$
\begin{gathered}
\text { Disease index }=\frac{\sum(\text { Disease level } \times \text { number of diseased plants per level })}{\text { Total number of palnts } \times 4} \times 100 \\
\text { Germination rate }=\frac{\text { Number of the spores germinated }}{\text { Total number of the spores }} \times 100
\end{gathered}
$$

As 3 plots were repeated for each treatment, all the data were calculated separately for each plot, with 3 values per treatment. All data were subjected to the analysis of variance using SPSS v23 (IBM SPSS, Somers, NY, USA). The least significant difference (LSD) test was used to determine the significance of the differences between the treatments. 


\section{Results}

\subsection{Antagonistic Effect of Streptomyces Strains against V. dahliae}

In the confrontation culture, there was a transparent zone of inhibition with an average diameter of $2.2 \mathrm{~cm}$ surrounding the agar plugs of strain Act7. In this transparent zone, the growth of $V$. dahliae was completely inhibited. Compared with the control, the cell-free culture filtrate of strain Act7 inhibited the colony growth of $V$. dahliae by $80.4 \%$, while the inhibition rate of spore germination was $84.7 \%$ (Table 1). Strain Act28 showed similar inhibitory effects on the growth of $V$. dahliae.

Table 1. Inhibitory effect of Streptomyces strains Act27 and Act28 on colony growth and spore germination of Verticillium dahliae.

\begin{tabular}{ccccccc}
\hline \multirow{2}{*}{ Treatment } & \multicolumn{2}{c}{ Growth-Inhibition Zone } & \multicolumn{2}{c}{ Colony Growth } & \multicolumn{2}{c}{ Spore Germination } \\
\cline { 2 - 7 } & Diameter (Cm) & Transparency & $\begin{array}{c}\text { Colony } \\
\text { Diameter (Cm) }\end{array}$ & $\begin{array}{c}\text { Inhibition Rate } \\
(\%)\end{array}$ & $\begin{array}{c}\text { Germination } \\
\text { Rate (\%) }\end{array}$ & $\begin{array}{c}\text { Inhibition Rate } \\
(\%)\end{array}$ \\
\hline Control & - & - & 5.8 & - & 83.5 & - \\
Act7 & 2.2 & ++ & 1.7 & 80.4 & 12.8 & 84.7 \\
Act28 & 1.9 & ++ & 2.2 & 70.6 & 23.5 & 71.9 \\
\hline
\end{tabular}

The transparency of the growth inhibition zone refers to the degree of growth inhibition of the target pathogen within this zone; ++ indicates that the pathogen was completely inhibited and the zone was transparent.

\subsection{Identification of Streptomyces Strain Act7}

A phylogenetic tree was constructed based on the $16 \mathrm{~S}$ rDNA sequences of strain Act7 and other related Streptomyces strains, including strain Act28 (Streptomyces globisporus, MH918504.1) (Figure 1). Strain Act7 formed a cluster with S. globisporus, and their sequence identities reached $99.86-99.93 \%$. In particular, strain Act7 shared a sequence identity of 99.93\% with S. globisporus subsp. globisporus (JQ066793.1). Thus, we tentatively classified strain Act7 as Streptomyces globisporus subsp. globisporus.

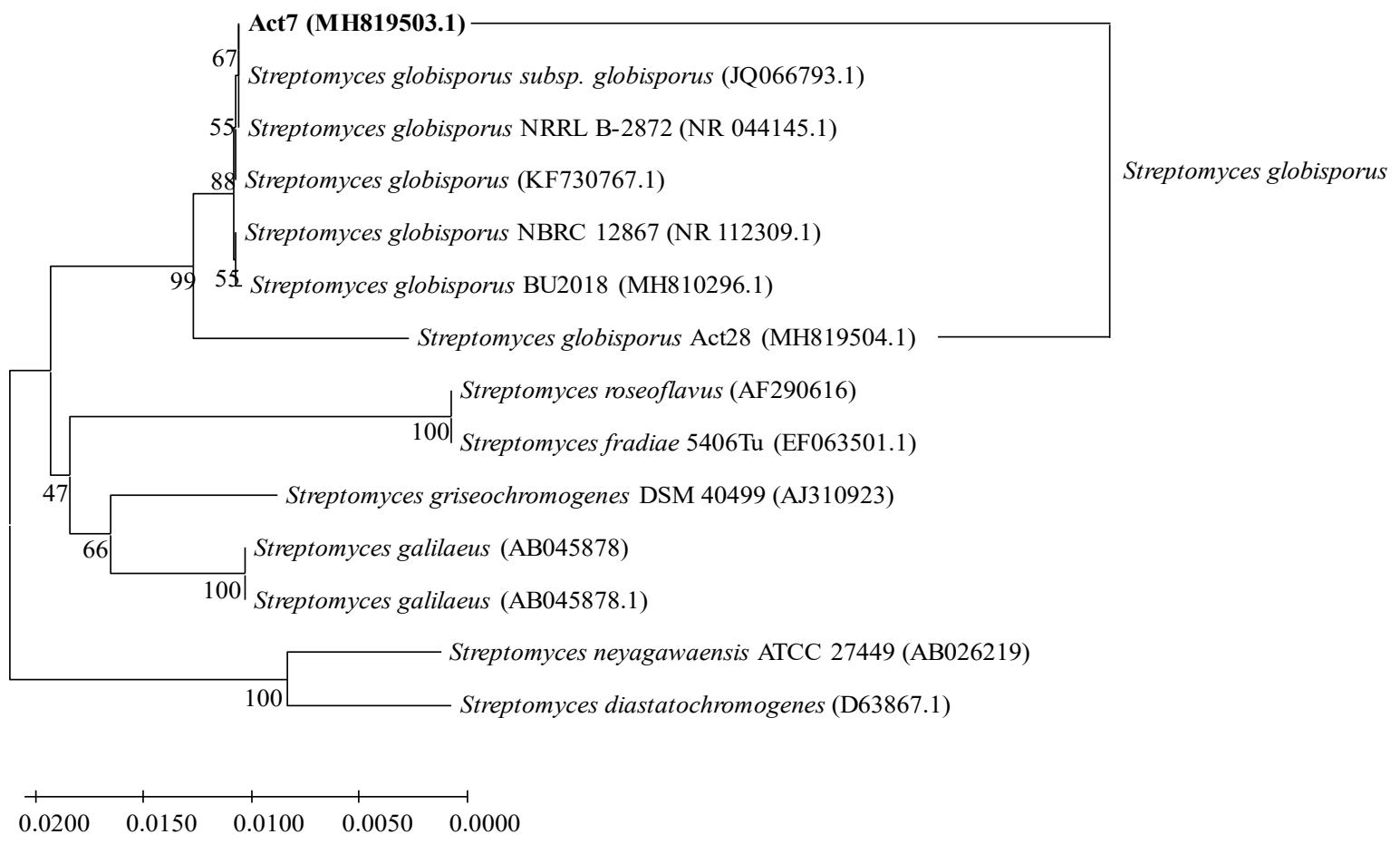

Figure 1. Phylogenetic tree based on $16 \mathrm{~S}$ rDNA sequences of strain Act7 from this study and related Streptomyces strains from the GenBank database. 


\subsection{Growth-Promoting Effect of Streptomyces Preparations on Cotton Seedlings}

Compared with the control, the seed-coating treatments with different Streptomyces preparations showed significant effects on the leaf greenness and leaf area of cotton seedlings grown in V. dahliae-infected soil (Figure 2). The leaf greenness of LA7-, IA7, and DLA7-treated seedlings was improved by 55.5\%, 50.0\%, and 70.1\%, respectively. Meanwhile, the leaf area of LA7- and DLA7-treated seedlings was increased by $235.9 \%$ and $215.4 \%$, respectively. The leaf greenness of DLA28-treated seedlings was improved by $42.4 \%$. Meanwhile, the leaf area of DLA28-treated seedlings was increased by $191.5 \%$.

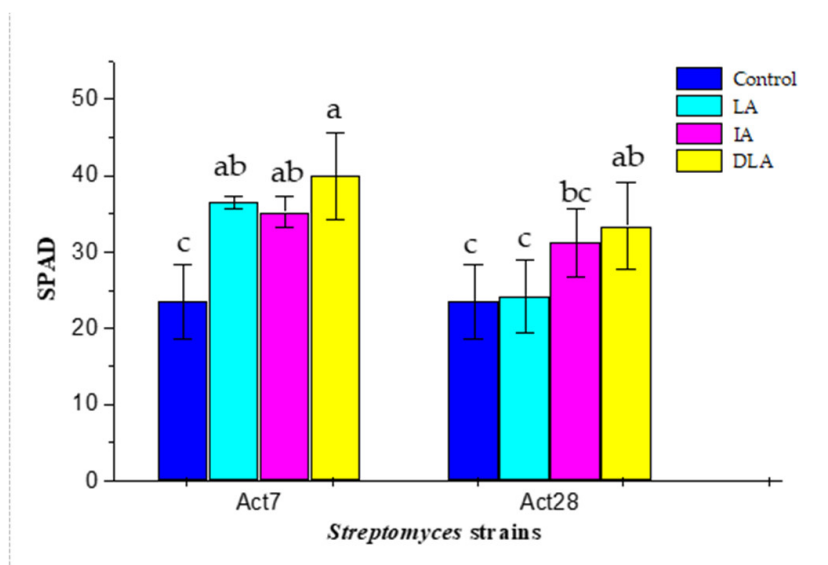

(a)



(b)

Figure 2. Effect of seed coating with living (LA), inactivated (IA), and diluted living (DLA) reparations of Streptomyces strains Act7 and Act28 on leaf greenness and leaf area of cotton seedlings after the two euphylla fully expanded. Different lowercase letters in the same column indicate significant differences between the treatments by LSD test $(p<0.05)$. (a) Leaf greenness index (SPAD value); (b) leaf area.

\subsection{Root Vitality}

There was no significant difference in the root vitality of cotton seedlings between the LA7 treatment and the control (Figure 3). However, both the IA7 and DLA7 treatments significantly improved the root vitality by $69.1 \%$ and $75.8 \%$, respectively, compared with the control $(p<0.05)$. Treatments with the seed-coating preparations of strain Act28 showed a similar effect on the root vitality.

\subsection{Disease Index}

The disease index of Verticillium wilt occurred when the leaves changed from green to yellowish-brown. The disease index of Verticillium wilt was considerably reduced in cotton seedlings after the LA7, IA7, and DLA7 treatments compared with the control (Figure 4). The greatest reduction was observed in DLA7-treated seedlings (66.7\%), followed by those treated with LA7 $(31.9 \%)$ and IA7 $(25.0 \%)$. The seed-coating preparations of Act28 showed a similar effect on the disease index of Verticillium wilt. 


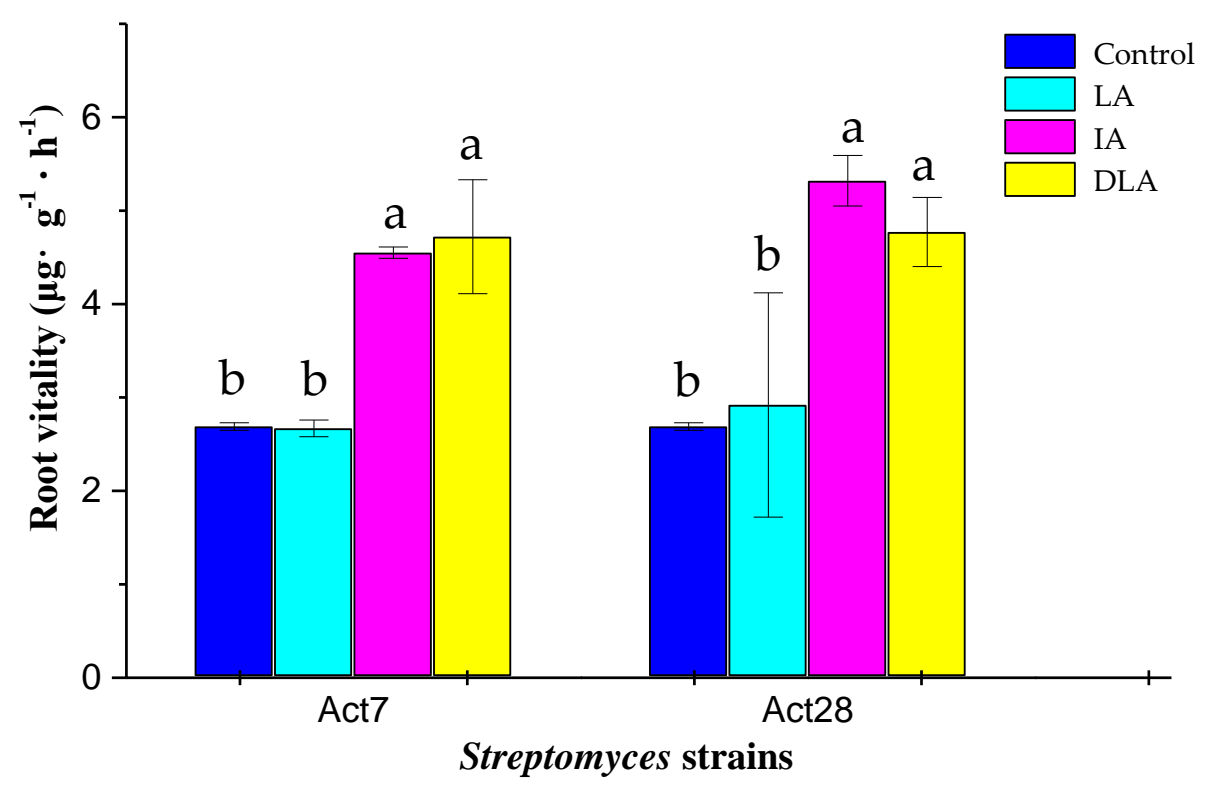

Figure 3. Effect of seed coating with living (LA), inactivated (IA), and diluted living (DLA) preparations of Streptomyces strains Act7 and Act28 on root vitality of cotton seedlings. Different lowercase letters in the same column indicate significant differences between the treatments by LSD test $(p<0.05)$.

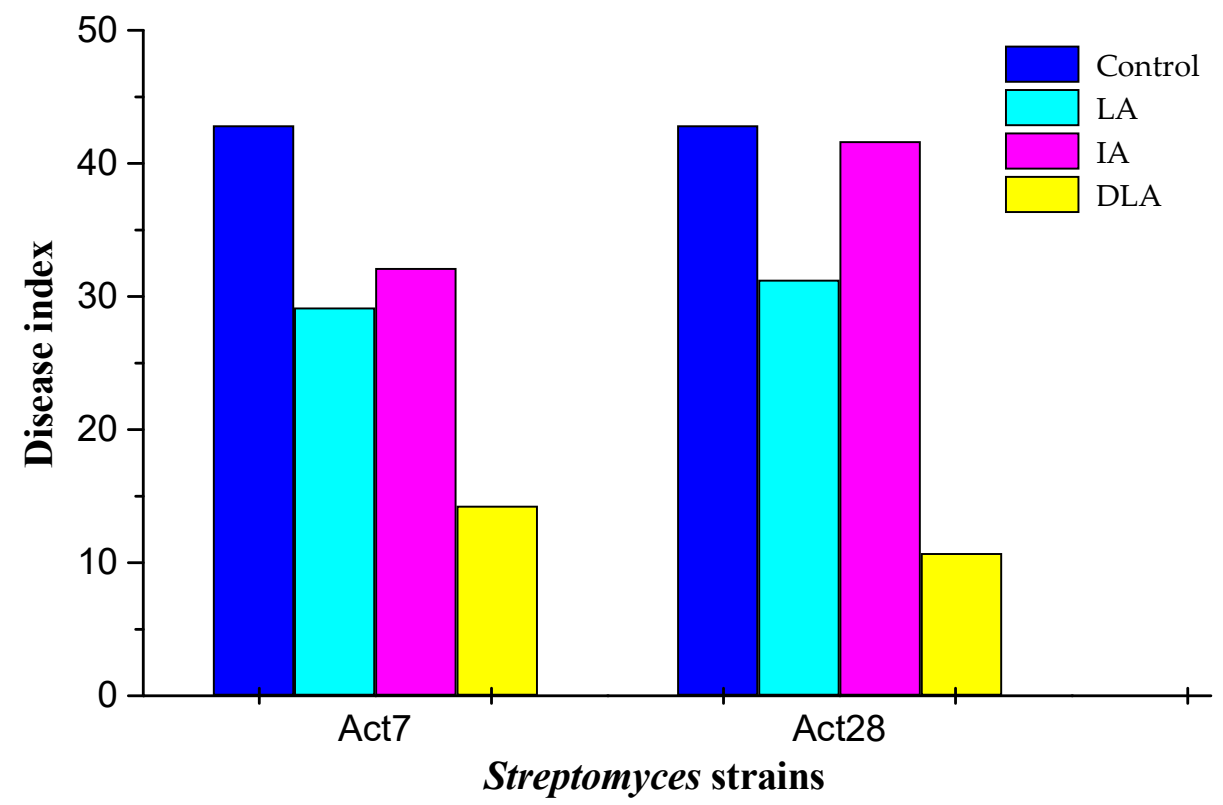

Figure 4. Effect of seed coating with living (LA), inactivated (IA), and diluted living (DLA) preparations of Streptomyces strains Act7 and Act28 on the disease index of cotton seedlings.

\section{Discussion}

The application of Streptomyces strains as biocontrol agents can promote plant growth and control Verticillium wilt in cotton $[17,23]$. However, whether these beneficial effects can be attributed to the living cells (spores) or the active metabolites produced by the living cells (spores) is still unclear. In particular, it remains unknown whether the presence of excessive viable spores has adverse effects on plant growth promotion and/or disease control. To answer this question, we compared the effects of seed coating with different preparations of living S. globisporus containing high (LA) and low (DLA) concentrations of viable spores. 
In this study, we found that compared with the control, seed coating with the inactivated preparations of $S$. globisporus (the IA treatments) also substantially increased the leaf greenness and root vitality of cotton seedlings under attack by $V$. dahliae. This phenomenon indicated that in addition to viable spores, the effective components in the living preparations also contained active metabolites. The metabolites with a plant growth-promoting effect possessed high resistance to heat at high temperatures, and they could maintain their effect even after dry-heat sterilization $\left(170^{\circ} \mathrm{C}, 2 \mathrm{~h}\right)$.

The active metabolites in the seed-coating preparations of living Streptomyces are mainly plant hormones. Plant growth hormones such as indole-3-acetic acid, 6-benzylamino purine, kinetin, abscisic acid, and others have been found in the metabolites from $S$. rochei D74 and S. pactum Act12 [11]. Therefore, we considered that the active metabolites in the seed-coating preparations of $S$. globisporus were highly likely plant hormones

It is worth noting that this study was carried out on an infected soil inoculated with a large quantity of $V$. dahliae (containing $2.9 \times 10^{7} \mathrm{~g}^{-1}$ ). Hence, the effects of seed coating with the living preparations of $S$. globisporus on plant growth promotion and disease control of cotton were achieved under substantial stress caused by the pathogen. Compared with the control, the DLA treatment improved root vitality by $75.8-77.4 \%$, and reduced the disease index by $66.7-70.8 \%$. The experimental results from the simulated soil containing a large quantity of $V$. dahliae indicated that seed coating with the living preparations of $S$. globisporus was an effective approach to reduce soil sickness caused by continuous cropping of cotton. Field experiments should be carried out to verify these beneficial effects and clarify the underpinning mechanisms.

In summary, the seed-coating preparations from living S. globisporus contributed to plant growth of cotton seedlings through the combined action of viable cells and active metabolites. Only at an appropriate concentration of viable spores could the living preparations achieve their maximal effect on plant growth promotion of cotton seedlings and effectively reduce the incidence of Verticillium wilt under attack by $V$. dahliae. An excess of viable spores, along with high concentrations of secondary active metabolites, may limit the plant growth-promoting effect and even negatively affect plant growth. The powder of living $S$. globisporus prepared by solid-state fermentation has multiple advantages, such as easy culturing, high yield, and long-term survival of spores, and the simple procedure of seed coating. These preparations from living $S$. globisporus may provide a new approach to control Verticillium wilt of cotton in practical production.

\section{Conclusions}

The active components in the seed-coating preparations of living S. globisporus Act7 and Act 28 can be divided into viable spores and active metabolites, such as plant growthregulating hormones. Seed coating with an appropriate dose of the living preparations can considerably promote leaf growth and improve root vitality of cotton seedlings, while reducing the disease index of Verticillium wilt in cotton under attack by V. dahliae, by the function of both viable spores and their active metabolites.

Author Contributions: Investigation, S.B., Y.L., C.D., and J.Z.; data curation, Q.C.; writing-original draft preparation, Q.C.; writing-review and editing, Q.X. and T.Z.; All authors have read and agreed to the published version of the manuscript.

Funding: This research was funded by the National Natural Science Foundation of China (grant numbers 41831284, 41907148, and 42001097) and the General Project of the Fundamental Research Funds for the Central Universities of China (grant numbers GK202103128 and GK202003099).

Data Availability Statement: The sequencing data of Act7 and Act28 presented in this study are openly available in [National Center for Biotechnology Information (NCBI)] at [https:/ /www.ncbi. nlm.nih.gov/nuccore/JQ066793.1/] (accessed on 1 May 2021) and [https:/ / www.ncbi.nlm.nih.gov/ nuccore/MH918504.1/] (accessed on 1 May 2021), reference number [JQ066793.1] and [MH918504.1], respectively.

Conflicts of Interest: The authors declare no conflict of interest. 


\section{References}

1. Paplomatas, E.J. Incidence of Verticillium wilt and yield losses of cotton cultivars (gossypium hirsutum) based on soil inoculum density of Verticillium dahlia. Phytopathology 1992, 82, 1417-1420. [CrossRef]

2. Bejarano-Alczar, J.; Blanco-Lpez, M.A.; Melero-Vara, J.M.; Jimnez-Daz, R.M. The influence of Verticillium wilt epidemics on cotton yield in southern Spain. Plant Pathol. 2010, 46, 168-178. [CrossRef]

3. Wang, Y.; Liang, C.; Wu, S.; Zhang, X.; Tang, J.; Jian, G.; Jiao, G.; Li, F.; Chu, C. Significant improvement of cotton Verticillium wilt resistance by manipulating the expression of gastrodia antifungal proteins. Mol. Plant 2016, 9, 1436-1439. [CrossRef]

4. Zhang, Y.; Wang, X.; Rong, W.; Yang, J.; Li, Z.; Wu, L.; Zhang, G.; Ma, Z. Histochemical analyses reveal that stronger intrinsic defenses in Gossypium barbadense than in G. hirsutum are associated with resistance to Verticillium dahliae. Mol. Plant Microbe Interact. 2017, 30, 984-996. [CrossRef]

5. Wang, T.; Hao, Y.; Zhu, M.; Yu, S.; Ran, W.; Xue, C.; Ling, N.; Shen, Q. Characterizing differences in microbial community composition and function between Fusarium wilt diseased and healthy soils under watermelon cultivation. Plant Soil 2019, 438, 421-433. [CrossRef]

6. Hu, J.; Wei, Z.; Kowalchuk, J.A.; Xu, Y.; Shen, Q.; Jousset, A. Rhizosphere microbiome functional diversity and pathogen invasion resistance build up during plant development. Environ. Microbiol. 2020, 22, 5005-5018. [CrossRef]

7. Raaijmakers, J.M.; Paulitz, T.C.; Steinberg, C.; Alabouvette, C.; Moenne-Loccoz, Y. The rhizosphere: A playground and battlefield for soilborne pathogens and beneficial microorganisms. Plant Soil 2009, 321, 341-361. [CrossRef]

8. Berendsen, R.L.; Pieterse, C.M.J.; Bakker, P.A.H.M. The rhizosphere microbiome and plant health. Trends Plant Sci. 2012, 17, 478-486. [CrossRef]

9. Zhao, J.; Xue, Q.; Du, J.; Yu, Y.; Xue, L. Biocontrol effect of broad-spectrum antagonistic actinomycete on melon gummy stem blight. J. Northwest AF Univ. 2012, 40, 65-71. [CrossRef]

10. Li, H.; Guo, Q.; Jing, Y.; Liu, Z.; Zheng, Z.; Sun, Y.; Xue, Q.; Lai, H. Application of Streptomyces pactum Act12 enhances drought resistance in wheat. J. Plant Growth Regul. 2020, 39, 122-132. [CrossRef]

11. Ma, J.; Liu, Y.; Li, Y.; Sun, Y.; Yang, B.; Lai, H.; Xue, Q. Effects and mechanism of two strains on promoting plant growth and increasing grain yield of maize. Chin. J. App. Ecol. 2017, 28, 315-326. [CrossRef]

12. Li, Y.; Guo, Q.; Li, Y.; Sun, Y.; Xue, Q.; Lai, H. Streptomyces pactum Act12 controls tomato yellow leaf curl virus disease and alters rhizosphere microbial communities. Biol. Fertil. Soils 2019, 55, 149-169. [CrossRef]

13. Cao, S.; Wang, W.; Wang, F.; Zhang, J.; Wang, Z.; Yang, S.; Xue, Q. Drought-tolerant Streptomyces pactum Act12 assist phytoremediation of cadmium-contaminated soil by Amaranthus hypochondriacus: Great potential application in arid/semi-arid areas. Environ. Sci. Pollut. Res. 2016, 23, 14898-14907. [CrossRef]

14. Mao, N.; Xue, Q.; Tang, M.; Wang, L.; Zhao, J.; Duan, C. Degradation of para-hydroxybenzoic acid by actinomyces and its effects on strawberry growth. J. Agric. Sci. Technol. Iran. 2010, 12, 103-108.

15. Chen, J.; Ma, Y.; Xue, Q. Use of microorganisms in controlling parasitic root weed Orobanche spp. Chin. J. Eco-Agric. 2018, 26, 49-56. [CrossRef]

16. Bai, S. Study on Screening of Biocontrol Actinomyces for Cotton Verticillium Wilt and Their Prophylaxis and Growth Promoting Effect. Master's Thesis, Northwest A\&F University, Yangling, China, 2009.

17. Xue, L. Studies on Mechanisms of Disease Resistance and Growth Promoting Effect of Biocontrol Streptomyces on Verticillium Wilt of Cotton. Ph.D. Thesis, Northwest A\&F University, Yangling, China, 2013.

18. Xue, L.; Wang, J.; Liu, C.; Xue, Q.; Shen, G.; Zhao, J. Inhibition of antagonistic Streptomyces spp. on microsclerotia formation and germination of Verticillium dahliae. Acta Phytophylacica Sin. 2012, 39, 289-296.

19. Xue, L.; Xue, Q.; Lu, J.; Shen, G.; Zhao, J. Influence of Verticillium dahliae mycelium on 4 types of extracellular hydrolases activity of Streptomyces. Acta Phytopathol. Sin. 2012, 42, 73-83. [CrossRef]

20. Xue, L.; Xue, Q.; Zhao, J.; Shen, G.; Tang, M.; Lu, J. Influence of Verticillium dahliae mycelium on extracellular proteases and antifungal activity of Streptomyces. Cotton Sci. 2012, 24, 78-84.

21. Wei, X.; Chen, J.; He, F.; Gu, M.; Wang, D.; Xue, L.; Xue, Q. Colonization and effects of antagonistic Streptomyces on leaf photosynthetic characteristics and growth of cotton seedlings. J. Northwest AF Univ. 2013, 41, 78-84. [CrossRef]

22. Chen, Q. The Remediation Techniques of Actinomycetes on Cotton Continuous Cropping Obstacle. Master's Thesis, Northwest A\&F University, Yangling, China, 2010.

23. Xue, L.; Xue, Q.; Chen, Q.; Lin, C.; Shen, G.; Zhao, J. Isolation and evaluation of rhizosphere actinomycetes with potential application for biocontrol of Verticillium wilt of cotton. Crop Prot. 2013, 43, 231-240. [CrossRef]

24. Xu, L.; Li, W.; Liu, Z.; Jiang, C. Actinomycte Systematic: Principle, Methods and praCtice, 1st ed.; Scientific Press: Beijing, China, 2007; pp. $40-45$.

25. Yan, C.; Quanhong, X.; Zhanquan, C.; Meiru, S.; Xiaofeng, S.; Jijun, A.; Rong, Z. Actinomycetes in chilli rhizosphere soil and on surface of chilli root from protectorate in Qinghai, China. Chin. J. Appl. Environ. Biol. 2003, 9, 92-96. [CrossRef]

26. Wang, S.; Tian, X.; Liu, T.; Lu, X.; You, D.; Li, S. Irrigation, straw, and nitrogen management benefits wheat yield and soil properties in a dryland agro-ecosystem. Agron. J. 2014, 106, 2193-2201. [CrossRef]

27. Ling, Q.; Huang, W.; Jarvis, P. Use of a SPAD-502 meter to measure leaf chlorophyll concentration in Arabidopsis thaliana. Photosynth. Res. 2011, 108, 1-13. [CrossRef] 
28. Richter, A.K.; Frossard, E.; Brunner, I. Polyphenols in the woody roots of Norway spruce and European beech reduce TTC. Tree Physiol. 2007, 27, 155-160. [CrossRef]

29. Wang, L.; Feng, H.; Teng, L.; Chen, X.; Dan, H.; Lu, S.; Xu, J.; Zhou, L. Effects of long-term cotton plantations on Fusarium and Verticillium wilt diseases infection in China. Afr. J. Agric. Res. 2012, 7, 1562-1565. [CrossRef] 